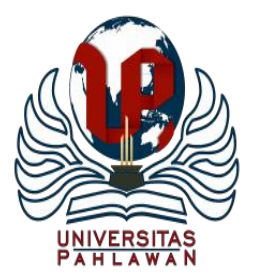

Jurnal Abdidas Volume 1 Nomor 3 Tahun 2020 Halaman 119 - 124 JURNAL ABDIDAS

Community Development Service on Educational and Health Sciences http://abdidas.org/index.php/abdidas

\title{
LATIHAN FISIK DALAM UPAYA PENCEGAHAN LOW BACK PAIN (LBP)
}

\author{
Edriyani Yonlafado Br. Simanjuntak ${ }^{1}$, Erwin Silitonga ${ }^{2}$, Novita Aryani ${ }^{3}$ \\ Program Studi Ners, Fakultas Farmasi dan Ilmu Kesehatan, Universitas Sari Mutiara, \\ Sumatera Utara, Indonesia ${ }^{1,2,3}$ \\ E-mail: edriyani260481@gmail.com ${ }^{1} \underline{\text { erwin.joy.silitonga@gmail.com }}{ }^{2} \underline{\text { novitaaryaniusm@gmail.com }}$
}

\begin{abstract}
Abtsrak
Cara mengatasi kondisi low back pain salah satu penatalaksaannya adalah fisioterapi. Hasil penelitian (Kusuma and Setiowati 2015) bahwa latihan fisik dengan pemberian William Flexion Exercise dapat meningkatkan lingkup gerak sendi penderita low back pain. Tujuan pengabdian masyarakat ini adalah: 1) untuk memberikan pendidikan kesehatan tentang latihan fisik dalam pencegahan low back pain (LBP), 2). agar masyarakat mengetahui pengaruh latihan fisik terhadap pencegahan low back pain (LBP) dan, 3) agar masyarakat dapat memahami latihan fisik dalam mencegah low back pain (LBP). Metode yang dilakukan adalah dengan cara memaparkan materi untuk meningkatkan pengetahuan dengan menggunakan power point dan leaflat dan demonstrasi langsung agar peserta terampil dalam melakukan latihan fisik William Flexion Exercise. Pendidikan kesehatan yang dilakukan pada peserta kegiatan setelah dievaluasi mereka mampu memahami, menjelaskan definisi, penyebab, tanda dan gejala, serta cara mengatasi low back pain. Mereka juga bersedia melakukan gerakan-gerakan tersebut di rumah secara mandiri sesuai panduan pada leaflat yang telah diterima.
\end{abstract}

Kata kunci: latihan fisik, low back pain

\section{Abstract}

One way to overcome the condition of low back pain is physiotherapy. (Kusuma and Setiowati 2015) research results that physical exercise with the provision of William Flexion Exercise can increase the scope of joint motion of patients with low back pain. The Objectives of Community Service are: 1) To provide health education about physical exercise in the prevention of low back pain (LBP). 2). So that people know the effect of physical exercise on preventing low back pain (LBP) and 3) So that people can understand physical exercise in preventing low back pain (LBP). The method used is by presenting material to increase knowledge by using power points and leaflets and direct demonstrations so that participants are skilled in physical exercise William Flexion Exercise. Health education is carried out on the participants of the activity after being evaluated they are able to understand, explain the definitions, causes, signs and symptoms, as well as how to deal with low back pain. They are also willing to do these movements at home independently according to the guidelines in the received leaflet.

Keywords: physical exercise, low back pain

Copyright (c) Edriyani Yonlafado Br. Simanjuntak, Erwin Silitonga, Novita Aryani

Corresponding author :

Address : Universitas Sari Mutiara Indonesia

Email : edriyani260481@gmail.com

ISSN 2721-9224 (Media Cetak)

Phone :

ISSN 2721- 9216 (Media Online)

DOI: https://doi.org/10.31004/abdidas.v1i3.21 


\section{PENDAHULUAN}

Low back pain (LBP) atau nyeri punggung bawah merupakan nyeri yang dirasakan pada daerah punggung bawah di daerah diskus invertebralis lumbal bawah L4-L5 dan L5-S, yang disertai nyeri menjalar hingga ke tumit kaki (Pheasant 1991). Kondisi ini dominan terjadi dapat dikarenakan duduk yang terlalu lama dan posisi yang salah sehingga menyebabkan otot punggung kaku yang dapat merusak jaringan disekitarnya (Harwanti, S \& Panuwun Joko Nur Cahyo 2018)

Berdasarkan WHO, low back pain merupakan masalah kesehatan yang sering dijumpai di masyarakat. Sekitar $70-80 \%$ penduduk negara maju mengalami low back pain dan 15$45 \%$ sebagai penderita dan 1:20 dirawat dengan serangan akut dengan rentang yang mengalami adalah usia 35-55 tahun. Hasil studi yang dilakukan menurut Mortimer, Pernold \& Wiktorin (2007); WHO (2013) dalam (Kusuma and Setiowati 2015) bahwa di negara berkembang 33\% penduduk mengalami nyeri persisten. Nyeri yang terjadi berhubungan depresi, sehingga mengganggu kualitas hidup dan kemampuan aktivitas pekerja. Hasil penelitiannya memberikan gambaran nyeri yang terjadi berupa neuralgia dengan $56 \%$ dialami di regio thorax, $13 \%$ di bagian wajah, $13 \%$ di regio lumbal dan $11 \%$ di regio servikal.

Menurut penelitian (Harwanti, S \& Panuwun Joko Nur Cahyo 2018) menunjukkan umur, kebiasaan olahraga, masa kerja mempengaruhi terjadinya low back pain. Wahab (2019) menyampaikan bahwa penyebab utama low back pain adalah faktor ergonomi. Berdasarkan
Bajwa \& Kaur dalam (Patrianingrum, Oktaliansah, and Surahman 2015) mengatakan faktor pencetus lainnya adalah pekerjaan yang memerlukan pengulangan gerakan berlebihan sehingga menimbulkan cedera otot dan saraf, posisi yang tidak mendukung, posisi statis atau diam tidak bergerak dalam jangka waktu lama, membungkuk, memutar serta waktu istirahat yang tidak memadai.

Untuk mengatasi kondisi low back pain salah satu penatalaksanaannya adalah fisioterapi. Berdasarkan Wibowo dalam (Kusuma and Setiowati 2015) adapun macam fisioterapi salah satunya adalah latihan fisik. Hasil penelitian (Kusuma and Setiowati 2015) bahwa latihan fisik dengan pemberian William Flexion Exercise dapat meningkatkan lingkup gerak sendi penderita low back pain. Selain itu penelitian (Harwanti, Ulfah, and Nurcahyo 2019) menunjukkan ada efek pemberian latihan peregangan dengan William Flexion Exercise terhadap pengurangan keluhan low back pain.

Tujuan pengabdian masyarakat ini adalah: 1) untuk memberikan pendidikan kesehatan tentang latihan fisik dalam pencegahan low back pain (LBP), 2) agar masyarakat mengetahui pengaruh latihan fisik terhadap pencegahan low back pain (LBP), dan 3) agar masyarakat dapat memahami latihan fisik dalam mencegah low back pain (LBP).

\section{METODE}

Segala pekerjaan yang dilakukan seseorang beresiko akan gangguan kesehatan salah satunya penyakit yang berkaitan gangguan muskuloskeletal. Sebagian orang menyadari 
bahwa penyakit tersebut kemungkinan karena pekerjaannya, terapi banyak orang juga yang tidak menyadari bahwa pekerjaan yang ditekuninya sebagai penyebab penyakit tertentu. Salah satu gangguan musculoskeletal yang sering dialami masyarakat yang bekerja adalah low back pain (LBP) atau dikenal dengan nyeri punggung bawah.

Low back pain dapat terjadi pada siapa saja yang mempunyai masalah kesehatan pada muskulokeletal seperti ketegangan lumbosacral akut, ketidakmampuan ligamen lumbosakral, kelemahan otot, osteoartritis, spinal stenosis, serta masalah pada sendi intervertebral, dan kaki yang tidak sama panjang. Berdasarkan paparan di atas, untuk meningkatkan pengetahuan dan keterampilan perlu pemaparan materi dan demonstrasi langsung kepada masyarakat. Adapun kegiatan pengabdian masyarakat yang dilakukan kepada peserta kegiatan adalah: 1) melakukan koordinasi dengan kepala lingkungan IX Kelurahan Gaharu, Kecamatan Medan Timur untuk izin pelaksanaan kegiatan pengabdian masyarakat, 2) penetapan tempat dan waktu kegiatan pengabdian masyarakat yang akan dilaksanakan, 3) pelaksanaan kegiatan dengan diawali perkenalan tim pengabdian masyarakat dengan masyarakat lingkungan IX Kelurahan Gaharu, Kecamatan Medan Timur, 4) memberikan pendidikan kesehatan terkait low back pain dan latihan fisik terkait latihan fisik William Flexion Exercise kepada masyarakat, 5) melakukan demostrasi latihan fisik William Flexion Exercise, pendampingan dan peserta kegiatan melakukan kegiatan tersebut dengan mandiri, 6) melakukan evaluasi kegiatan dengan menanyakan terkait konsep low back pain dan latihan fisik William Flexion Exercise. 7) menjelaskan kembali jawaban kurang tepat ketika dijawab peserta kegiatan pengabdian masyarakat, dan 8) menutup acara kegiatan pengabdian masyarakat.

\section{HASIL DAN PEMBAHASAN}

Berdasarkan pelaksanaan pengabdian kepada masyarakat pada hari Rabu, 4 Desember 2019 pukul 16.00 WIB dilaksanakan di Rumah Data/Kampung KB Lingkungan IX, Kelurahan Gaharu, Kecamatan Medan Timur, didapatkan hasil yaitu peserta kegiatan mendapat materi tentang low back pain menggunakan metode ceramah, dengan penyampaian materi dengan menggunakan power point dan leaflat.

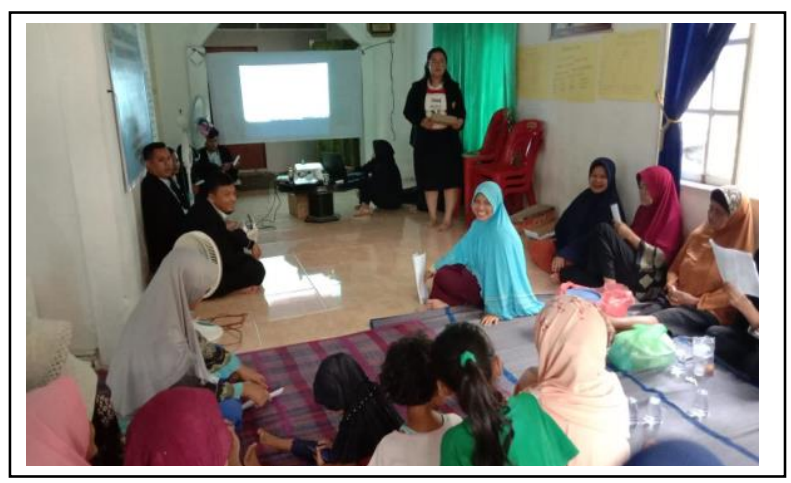

Gambar 1. Pemberian Pendidikan Kesehatan Low back pain Kepada Peserta Kegiatan

Dilakukan demonstasi latihan fisik William Flexion Exercise kemudian yang diikuti oleh peserta kegiatan dan diakhiri dengan latihan fisik secara mandiri. Kegiatan tanya jawab dilakukan setelah selesai pemberian materi dan demostrasi latihan fisik William Flexion Exercise. Kemudian, 
dilaksanakan evaluasi untuk mengidentifikasi kemampuan pemahaman peserta dan kemampuan latihan fisik William Flexion Exercise yang telah diajarkan. Hal ini dilakukan untuk mengetahui respon peserta kegiatan terhadap materi yang diberikan.

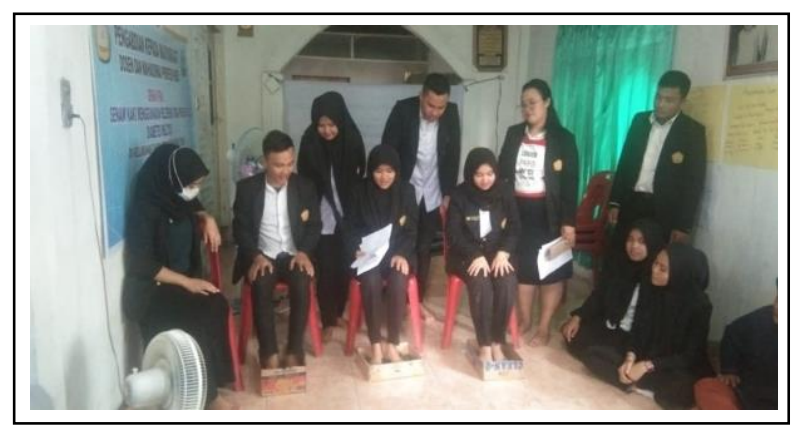

Gambar 2. Demonstrasi Latihan Fisik William Flexion Exercise

Metode evaluasi yang dilakukan pada akhir penyampaian materi untuk mengetahui tingkat pengetahuan peserta setelah pemberian materi tentang low back pain dan latihan fisik William Flexion Exercise. Hasil dari pendidikan kesehatan yang dilakukan pada masyarakat sebagai peserta kegiatan adalah peserta kegiatan mampu memahami dan menjelaskan definisi low back pain, penyebab low back pain, tanda dan gejala low back pain, dan cara mengatasi low back pain. Turut juga dijelaskan terkait latihan fisik William Flexion Exercise terkait definisi dan tujuan latihan fisik William Flexion Exercise.

Metode lainnya yang diberikan kepada peserta dengan metode demonstrasi melakukan latihan fisik William Flexion Exercise kepada peserta kegiatan di Lingkungan IX, Kelurahan Gaharu, Kecamatan Medan Timur. Peserta kegiatan dianjurkan untuk melakukan latihan fisik William Flexion Exercise dengan gerakan ke-1: Pelvic Tilt; gerakan ke-2: Knee To Chest; gerakan ke-3: Hip Rolling; gerakan ke-4: Pelvic Lift; gerakan ke-5; Lower Abdominal Exercise dan gerakan ke-6: Hip Extension.

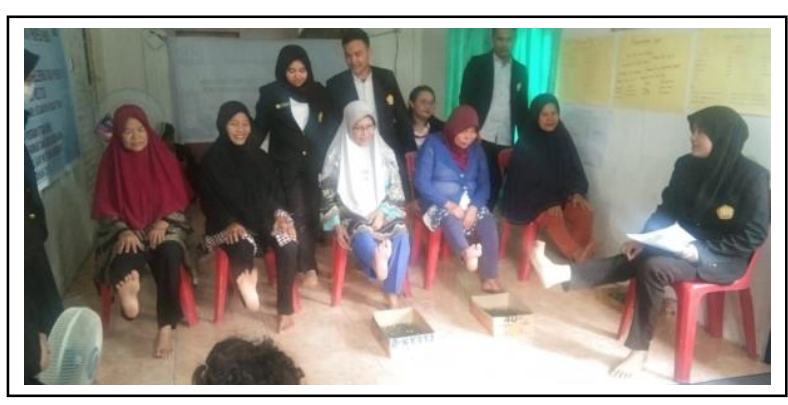

Gambar 3. Pendampingan Melakukan Latihan Fisik William Flexion Exercise

\section{Latihan fisik William Flexion Exercise} dapat dilakukan di rumah 3 kali seminggu selama 20 menit untuk mengurangi nyeri punggung bawah yang dialaminya oleh masyarakat ataupun peserta kegiatan. Hasil latihan fisik ini dapat dilakukan sekitar 4-5 minggu untuk memberikan hasil yang maksimal.

Pendidikan kesehatan yang dilakukan oleh tim pengabdian masyarakat di Lingkungan IX Kelurahan Gaharu, Medan Timur berjalan dengan sangat lancar. Masyarakat antusias dalam kegiatan pendidikan kesehatan. Berdasarkan hasil observasi peserta kegiatan berusia dewasa akhir dan didominasi perempuan. Berdasarkan penelitian (Goin, Pontoh, and Umasangadji 2019) menunjukkan karakteristik penderita nyeri punggung bawah didominasi kelompok kelompok usia 61-70 tahun dan rata-rata jenis kelamin lakilaki dan wanita sama memiliki masalah nyeri 
punggung bawah. Ini artinya lebih banyak dialami oleh lanjut usia dan berdasarkan jenis kelamin porsi laki-laki sama dengan perempuan.

Zaman sekarang ini tidak ada lagi perbedaan gender dalam melakukan pekerjaan. Pekerjaan laki-laki telah dikerjakan perempuan demikan juga pekerjaan perempuan telah dikerjakan laki-laki sehingga cenderung tidak ada perbedaan antara perempuan dan laki-laki. Persamaan itu menyebabkan baik laki-laki perempuan memiliki peluang yang sama melakukan pekerjaan sehingga posisi kerja yang salahpun dapat dialami mereka. Hasil penelitian (Kusuma and Setiowati 2015) bahwa posisi kerja memiliki pengaruh terhadap kejadian low back pain. Akibat posisi yang salah seperti membungkuk, memutar, mengangkat beban maupun duduk dan berdiri yang lama menyebabkan tekanan pada tulang belakang sehingga menyebabkan nyeri punggung bawah. Sejalan dengan penelitian (Goin, Pontoh, and Umasangadji 2019), bahwa pekerjaan monoton dan dilakukan terus-menerus dapat menimbulkan gangguan muskuloskeletal. Berdasarkan hal tersebut sering sekali terjadi di masyarakat sehingga menghambat dan menganggu produktivitas kerja mereka. Dalam mengantisipasi keadaan ini salah satu terapi modalitas yang membantu pengurangan nyeri punggung bawah adalah dengan latihan fisik William Flexion Exercise.

$$
\text { Berdasarkan Luklukaningsih dalam }
$$

(Kusuma and Setiowati 2015) latihan fisik William Flexion Exercise merupakan terapi latihan yang diperkenalkan Dr. Paul Williams pada tahun 1937. Latihan fisik William Flexion Exercise ini berfungsi untuk menurunkan rasa nyeri pada pinggang dengan memperkuat otot-otot yang memfleksikan lumbo sacral spine, khususnya otot abdominal dan otot gluteus maksimus dan meregangkan kelompok ekstensor punggung bawah. Latihan ini membantu penderita low back pain sehingga kemampuan gerak sendi pada area tulang pelakang dapat dimaksimalkan. Oleh karena itu, latihan fisik William Flexion Exercise sangat bermanfaat bagi orang yang mengalami nyeri punggung bawah dan dapat dilakukan 3 kali dalam seminggu dengan waktu latihan 20 menit. Hasil maksimal dapat diperoleh bila peserta dapat melakukan latihan fisik William Flexion Exercise dengan waktu sekurangnya 4-5 minggu dimana dapat mengurangi nyeri punggung bawah dan mengurangi kekakuan pada area tulang belakang.

\section{KESIMPULAN}

Kegiatan pendidikan kesehatan terlaksana sesuai dengan tujuan dan rencana yang disusun. Kegiatan ini mendapat sambutan yang baik dari peserta dan kegiatan ini memberikan imformasi yang baru bagi peserta mengenai pemberian pendidikan kesehatan low back pain dengan latihan fisik William Flexion Exercise untuk mengurangi low back pain pada masyarakat di Lingkungan IX, Kelurahan Gaharu Kecamatan Medan Timur. Saran yang dapat diberikan adalah perlunya kegiatan seperti ini dapat dilanjutkan pada masyarakat di daerah lain dan hasil kegiatan masih perlu dikembangkan agar kejasama dengan 
pihak pemerintah dan lintas sektor serta program dapat lebih ditingkatkan.

\section{UCAPAN TERIMA KASIH}

Pada kesempatan ini penulis mengucapakan terima kasih yang sebesar-besarnya kepada Lurah Kelurahan Gaharu atas kesempatan dan upaya dalam membantu penulis dengan memberi izin dan bahkan membantu untuk menyebarluaskan informasi, dan menyiapkan tempat untuk kelancaran kegiatan tersebut. Penulis juga mengucapkan terima kasih kepada unsur pimpinan Universitas Sari Mutiara Indonesia yang telah banyak membantu dalam urusan administrasi maupun dukungan tranfortasi kegiatan tersebut.

\section{DAFTAR PUSTAKA}

Goin, Zhari Zafitri, Lely M Pontoh, and Hilmi Umasangadji. 2019. "Karakteristik Punggung, Nyeri Di, Bawah Rehabilitasi, Poliklinik Sakit, Rumah Kota, Daerah Kepulauan, Tidore.” Kieraha Medical Jurnal 1(1): 44-53.

Harwanti, S \& Panuwun Joko Nur Cahyo, P.J.N. 2018. "Pengaruh Latihan Peregangan (William Flexion Exercise) Terhadap Penurunan Low back pain Pada Pekerja Batik Tulis Di Desa Papringan Kecamatan Banyumas." In Prosiding Seminar Nasional Dan Call For Papers Pengembangan Sumber Daya Perdesaan Dan Kearifan Lokal Berkelanjutan VIII 14-15 November 2018.,.

Harwanti, Siti, Nur Ulfah, and Panuwun Joko Nurcahyo. 2019. "Faktor-Faktor Yang Berpengaruh Terhadap Low back pain (Lbp) Pada Pekerja Di Home Industri Batik Sokaraja Kabupaten Banyumas." Kesmas Indonesia 10(2): 12.

Kusuma, Hangga, and Anies Setiowati. 2015. "Pengaruh William Flexion Exercise Terhadap Peningkatan Lingkup Gerak Sendi Penderita Low back pain." JSSF (Journal of
Sport Science and Fitness) 4(3): 16-21.

Patrianingrum, Meilani, Ezra Oktaliansah, and Eri Surahman. 2015. "Prevalensi Dan Faktor Risiko Nyeri Punggung Bawah Di Lingkungan Kerja Anestesiologi Rumah Sakit Dr. Hasan Sadikin Bandung." Jurnal Anestesi Perioperatif 3(1): 47-56.

Pheasant, Stephen. (1991). 1991. No TitleErgonomics,Work, and Health. Aspen Publiser Inc, USA. 